\title{
CARACTERIZAÇÃO DA POPULAÇÃO DE CÃES E GATOS EM UM BAIRRO NO MUNICÍPIO DE JABOTICABAL/SP
}

\author{
CHARACTERIZATION OF THE POPULATION OF DOGS AND CATS IN A \\ NEIGHBORHOOD IN JABOTICABAL/SP
}

\author{
M. B. D. OLIVARI ${ }^{1 *}$, B. F. IZOLA ${ }^{1}$, N. C. MARQUES ${ }^{1}$, F. S. MAIROS ${ }^{1}$, J. H. B. TOSCANO ${ }^{1}$, \\ A. P. R. GRISOLIO ${ }^{1}$, E. M. N. PAULA ${ }^{1}$, A. A. B. CARVALHO ${ }^{1}$
}

\section{RESUMO}

O controle populacional de cães e gatos é importante dentro das políticas públicas de saúde e preocupa as autoridades sanitárias, especialmente em relação à disseminação de zoonoses. O diagnóstico alcançado estabelece dados e caracteriza a população de cães e gatos. O trabalho objetivou caracterizar a população de cães e gatos do bairro Jardim das Rosas, localizado no município de Jaboticabal/SP e avaliar sua dinâmica, assim como a guarda responsável. Os dados do estudo foram obtidos por meio de entrevistas nas residências do bairro no período do mês de outubro de 2014. Foram utilizados questionário semiestruturado com perguntas a respeito dos animais de estimação. As informações foram organizadas em uma planilha de dados no programa Microsoft Excel ${ }^{\circledR}$ e em seguida, foram feitas as análises necessárias ao estudo. Foram visitadas 159 residências, sendo entrevistada uma pessoa por imóvel. 120 munícipes afirmaram possuir cães e/ou gatos; e 209 animais foram caracterizados. Quanto à vacinação, 85\% (178/209) dos animais foram vacinados no último ano, sendo que 75\% (158/209) receberam vacina contra a raiva. Quanto ao conhecimento sobre guarda responsável, 15\% (33/209) dos animais foram adquiridos em outra cidade, 22\% (46/209) ficaram doentes nos últimos 6 meses; $68 \%$ dos animais saem às ruas e destes, $66 \%$ (96/146) sem o uso de guias e $40 \%(58 / 146)$ não são castrados. Do total de entrevistados que possuíam animais de estimação, 24\% (28/120) disseram ter animais que tiveram pelo menos uma cria, obtendo-se uma média de 5,4 filhotes/animal em 2014. Tendo em vista que, apesar da cobertura vacinal ter sido satisfatória, não abrangeu os $80 \%$ esperados, aliada a existência de animais soltos nas ruas sem o devido acompanhamento, é necessário um trabalho de conscientização permanente para a guarda responsável e importância do controle de zoonoses em todo o município.

PALAVRAS-CHAVE: SAÚDE PÚBLICA VETERINÁRIA. GUARDA RESPONSÁVEL. QUESTIONÁRIO. ÁREA TEMÁTICA: Saúde Pública.

\footnotetext{
${ }^{1}$ Faculdade de Ciências Agrárias e Veterinárias da Universidade Estadual Paulista (UNESP) - Câmpus de Jaboticabal

* ma.beanucci@gmail.com
} 